Abstracted/indexed in Academic Search Complete, Asia Journals Online, Bangladesh Journals Online, Biological Abstracts, BIOSIS Previews, CAB Abstracts, Current Abstracts, Directory of Open Access Journals, EMBASE/Excerpta Medica, Google Scholar, HINARI (WHO), International Pharmaceutical Abstracts, Open J-gate, Science Citation Index Expanded, SCOPUS and Social Sciences Citation Index

ISSN: $1991-0088$

\title{
Effects of ondansetron alone and in combination with domperidone in the prevention of chemotherapy-induced nausea and vomiting in breast cancer patients
}

\author{
Kaberi Das Gupta1, A. K. M. Mosharrof Hossain'1, Abdur Raquib Jaigirdar², \\ Borhan Uddin', Tridiv Choudhury ${ }^{2}$ and Dipti Rani Saha ${ }^{1}$
}

${ }^{1}$ Department of Pharmacology, Sylhet M. A. G. Osmani Medical College, Sylhet 3100; ${ }^{2}$ Department of Radiotherapy, Sylhet M. A. G. Osmani Medical College, Sylhet 3100, Bangladesh.

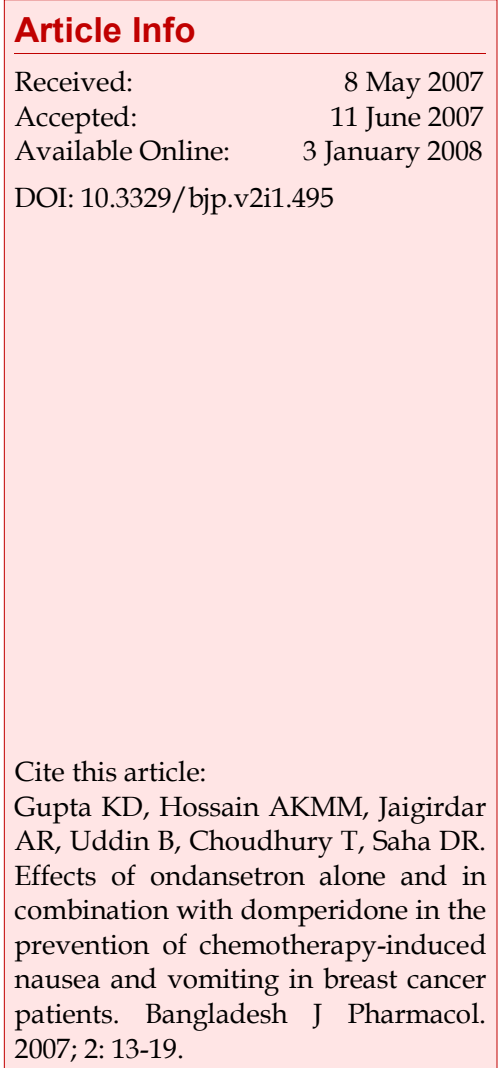

\begin{abstract}
The efficacy and safety of ondansetron, administered alone and in combination with domperidone to prevent chemotherapy-induced nausea and vomiting of breast cancer patients receiving chemotherapy FAC regimen (5-fluorouracil, adriamycin and cyclophosphamide) were evaluated. A consecutive open-label interventional study was conducted on a total number of 86 female breast cancer patients who were receiving chemotherapy. Forty two patients received ondansetron $(8 \mathrm{mg})$ intravenously $30 \mathrm{~min}$ before chemotherapy which is followed by ondansetron $(8 \mathrm{mg})$ administered orally every 8 hourly for 2 days from the day of start of chemotherapy. Another 44 patients received ondansetron $(8 \mathrm{mg})$ intravenously $30 \mathrm{~min}$ before chemotherapy followed by ondansetron $(8 \mathrm{mg})$ plus domperidone $(20 \mathrm{mg})$ administered orally 8 hourly for 48 hours from the day of start of chemotherapy. The number of emetic episodes, severity of nausea, assessment of appetite and adverse events were recorded at 8 hours intervals for two days study period using specific scoring criteria. Ondansetron in combination with domperidone significantly decreased the chemotherapy-induced nausea and vomiting in comparison with ondansetron administered alone $(\mathrm{p}<0.001)$. Appetite status was good with combination therapy $(p<0.001)$. Improvement in appetite indicates that ondansetron plus domperidone exert protective effect against nausea and maintain normal appetite, while patients who were getting monotherapy experience loss of appetite. The common adverse event, headache was present in both the groups. No extrapyramidal reaction was observed in any group. This study showed that ondansetron plus domperidone exert more pronounced antiemetic effect in patients with breast cancer receiving moderately emetogenic chemotherapy (FAC regimen) with good appetite status and less adverse effect.
\end{abstract}

\section{Introduction}

Breast cancer is the commonest form of malignancy in Western countries and accounts for $12 \%$ of all cancers,
$10 \%$ of all cancer deaths and $20-25 \%$ of all female cancer deaths. Worldwide there are 500,000-700,000 new cases annually (Bomford et al., 1993). It is estimated that in 2002 more than 175,000 women in the United States 
were diagnosed with breast cancer and that more than 43,000 of these women died (Rodabaugh and Bloss, 2001).

Prevalence of breast cancer in female is also remarkable in Bangladesh like that of other developing countries. There is no perfect data about the carcinoma breast among the whole population of Bangladesh. In a study, among the total number of 23,820 patients treated in the Cancer Department of Dhaka and Chittagong Medical College Hospital and Kumudini Hospital, Tangail during the period of 1964-1977, it is found that breast cancer is the 3rd most common malignant disease among females with an incidence of $14.5 \%$ (Huq, 1980).

Six cycles of 5-fluorouracil, doxorubicin, and cyclophosphamide (FAC regimen) or 5-fluoro-uracil, epirubicin, and cyclophosphamide (FEC) is considered standard adjuvant therapy for breast cancer (Bonadonna, 1988). This regimen is emetogenic, inducing nausea and vomiting in $60-90 \%$ of patients not treated with antiemetic drug (Clavel et al., 1995). The objective response rates to combination chemotherapy are generally higher $(60 \%)$ but with greater toxicity (Bomford et al., 1993).

Chemotherapy-induced nausea and vomiting, is one of the most common and most incapacitating experiences of patients undergoing cancer chemotherapy that can lead to electrolyte imbalance, dehydration, cachexia, and malnutrition. Poorly controlled chemotherapyinduced nausea and vomiting lead patients to refuse further treatment (Hesketh et al., 1994).

Commonly used antiemetic agents are metoclopramide, domperidone, selective serotonin $\left(5-\mathrm{HT}_{3}\right)$ receptor antagonists, etc. Selective $5-\mathrm{HT}_{3}$ receptor antagonists were first introduced in the mid-1980 and appear to prevent and control acute phase chemotherapy-induced nausea and vomiting (Gregory and Ettinger, 1998). 5$\mathrm{HT}_{3}$ receptor antagonists are ondansetron, granisetron, dolasetron and tropisetron. The most common adverse effects are headache, dizziness and constipation (McQuaid, 2004).

Ondansetron, a commonly used antiemetic, also has modest gastric prokinetic activity, which is attributed to its ability to act as an antagonist at $5-\mathrm{HT}_{3}$ receptors. It also may prolong colonic transit time, possibly by increasing colonic tone (Wilde and Markham, 1996). Metoclopramide is not used due to extrapyramidal symptom (EPS). Furthermore, the superiority of ondansetron (5- $\mathrm{HT}_{3}$ receptor antagonists) in the prevention of nausea and vomiting induced by a FAC chemo-therapy regimen has been demonstrated in a comparative study with metoclopramide (Metz, 1990). Domperidone is a $\mathrm{D}_{2}$-receptor antagonist with antinauseant and prokinetic effects. It enhances coordinated gastro intestinal motility and transit of material in the gastrointestinal tract.

Vomiting following breast cancer treated with emetogenic chemotherapy is troublesome. In control of CINV in breast cancer, no operational study has been carried out in our country to address this problem.

The aim of the present study is to compare anti-emetic effect of ondansetron plus domperidone with that of ondansetron administered alone in the prevention of chemotherapy-induced nausea and vomiting.

\section{Materials and Methods}

An open label, consecutive and interventional study was carried out during the period from January to December 2006. The patients admitted in Radiotherapy ward of with diagnosis of breast cancer diseases were taken as study population. Patients receiving FAC regimen for the treatment of breast cancer were the samples of this study as per inclusion and exclusion criteria designed for the study.

The study subjects (86) were divided in two groups. Forty two patients with odd registration number were enrolled in Group I (constituted the treatment armondansetron alone) while 44 patient with even registration number were enrolled in Group II (constituted the treatment arm ondansetron plus domperidone).

\section{Ondansetron-treated group}

Ondansetron (8 mg) was injected intravenously, $30 \mathrm{~min}$ before chemotherapy (FAC regimen) which is followed by ondansetron $(8 \mathrm{mg})$ administered orally every 8 hourly for 48 hours.

\section{Ondansetron plus domperidone-treated group}

Ondansetron (8 mg) was injected intravenously, $30 \mathrm{~min}$ before chemotherapy (FAC regimen) and is followed by ondansetron ( $8 \mathrm{mg}$ ) administered orally every 8 hourly for 48 hours plus domperidone ( $20 \mathrm{mg}$ ) 8 hourly for 48 hours from the day of start of chemotherapy.

Scoring for severity of nausea, the number of emetic episode and appetite assessment was conducted for 48 hours period. 
Table I

Effect of ondansetron administered alone and in combination with domperidone on chemotherapy-induced nausea, vomiting and appetite

\begin{tabular}{|lcccccc|} 
Hours & \multicolumn{2}{c}{ Score for nausea } & \multicolumn{2}{c}{ Score for vomiting } & \multicolumn{2}{c|}{ Score for appetite } \\
\cline { 2 - 7 } & Ondansetron & $\begin{array}{c}\text { Ondansetron plus } \\
\text { domperidone }\end{array}$ & Ondansetron & $\begin{array}{c}\text { Ondansetron plus } \\
\text { domperidone }\end{array}$ & $\begin{array}{c}\text { Ondansetron } \\
\text { Ondansetron plus } \\
\text { domperidone }\end{array}$ \\
\hline 8 & $1.6 \pm 1.2$ & $0.3 \pm 0.5^{\mathrm{a}}$ & $3.1 \pm 2.1$ & $0.5 \pm 0.9^{\mathrm{a}}$ & $1.4 \pm 0.9$ & $2.6 \pm 0.5^{\mathrm{a}}$ \\
16 & $1.9 \pm 0.9$ & $0.8 \pm 0.7^{\mathrm{a}}$ & $1.7 \pm 1.6$ & $1.0 \pm 1.1^{\mathrm{a}}$ & $1.1 \pm 0.8$ & $2.3 \pm 0.5^{\mathrm{a}}$ \\
24 & $2.0 \pm 0.6$ & $0.9 \pm 0.5^{\mathrm{a}}$ & $1.3 \pm 1.3$ & $0.7 \pm 0.9^{\mathrm{a}}$ & $1.0 \pm 0.7$ & $2.3 \pm 0.6^{\mathrm{a}}$ \\
32 & $1.4 \pm 0.59$ & $0.6 \pm 0.5^{\mathrm{a}}$ & $0.7 \pm 0.9$ & $0.1 \pm 0.2^{\mathrm{a}}$ & $1.1 \pm 0.8$ & $2.6 \pm 0.5^{\mathrm{a}}$ \\
40 & $1.1 \pm 0.4$ & $0.1 \pm 0.3^{\mathrm{a}}$ & $0.5 \pm 0.7$ & $0.1 \pm 0.3^{\mathrm{a}}$ & $1.4 \pm 0.8$ & $2.6 \pm 0.5^{\mathrm{a}}$ \\
48 & $0.6 \pm 0.6$ & $0.0 \pm 0.0^{\mathrm{a}}$ & $0.02 \pm 0.2$ & $0.0 \pm 0.0^{\mathrm{a}}$ & $1.9 \pm 0.8$ & $2.7 \pm 0.4^{\mathrm{a}}$ \\
\hline
\end{tabular}

Data are mean $\pm \mathrm{SD}$; aUnpaired t-test shows the significant difference between the two group at $\mathrm{p}<0.001$

Data were collected through preformed data collection sheet, from initiation of chemotherapy, every 8 hourly for 48 hours. Severity of nausea, episodes of vomiting, appetite status assessment, any sort of adverse-effects and necessity of any rescue medications were observed.

Episode of vomiting, severity of nausea and effect on appetite were assessed according to the standard scoring system (Stewart et al., 2000).

\section{Scoring the number of episode of vomiting}

Number of episode in 24 hours: None (score 0), 1 (score 1), 2 (score 2), 3 (score 3), 4 or more (score 4 ). An emetic episode is defined as a single vomit, or any number of continuous vomits. Emetic episodes are separated from one another by an absence of vomiting for at least 1 $\min$.

\section{Scoring for severity of nausea}

None (score 0 ), mild (loss of appetite without alteration in eating habits) score 1; moderate (oral intake decreased without significant weight loss, dehydration or malnutrition; IV fluids indicated $<24$ hours) score 2; severe (inadequate oral intake; IV fluids, tube feedings, indicated $\geq 24$ hours or life threatening consequences) score 3 .

\section{Scoring for appetite (Holdsworth et al., 1998)}

No appetite (not assessable) score 0, a little appetite (worse than usual) score1; some appetite (as usual) score 2; good appetite (better than usual) score 3.

\section{Statistical analysis}

All statistical analyses were done by SPSS software package, 12.0 for windows. Values were presented as mean \pm SD. $95 \%$ confidence limit with $p<0.05$ was taken as level of significance. Unpaired t-test was done to see any difference between two groups.

\section{Results}

The mean $( \pm$ SD) age for group I and II were $44.6 \pm 7.5$ years and $42.8 \pm 6.2$ years respectively. There was no significant difference of age distribution between two groups.

Effect of ondansetron administered alone and in combination with domperidone on chemotherapyinduced nausea is represented in Table I. The maximum score for nausea $(2.0 \pm 0.6)$ was observed at 24 hours after administering ondansetron. In case of both ondansetron and domperidone on chemotherapyinduced nausea, the maximum score was about half (0.9 $\pm 0.5)$ and was observed similarly at 24 hours of treatment. The differences between the two groups were highly significant at $1 \%$ level of significance in all hours. So, ondansetron and domperidone combination administered appears more effective than ondansetron alone in management of chemotherapy-induced nausea.

The maximum score for vomiting $(3.1 \pm 2.1)$ was observed at 8 hours after administering ondansetron. But in case of both ondansetron and domperidone on chemotherapy-induced vomiting, the maximum score was about one-third $(1.0 \pm 1.1)$ and was observed at 16 hours of treatment. The statistical analysis shows that the differences between the two groups were highly significant $p<0.001$ in all hours. So, it can be assumed that combination effect of ondansetron plus domperidone is better than ondansetron alone in 
Table II

Adverse events observed in ondansetron alone and ondansetron plus domperidone treated groups

\begin{tabular}{|c|c|c|c|c|}
\hline \multirow[t]{3}{*}{ Adverse events } & \multicolumn{4}{|c|}{ Number of cases } \\
\hline & \multicolumn{2}{|r|}{ Day 1} & \multicolumn{2}{|r|}{ Day 2} \\
\hline & Ondansetron & Ondansetron plus domperidone & Ondansetron & Ondansetron plus domperidone \\
\hline Headache & $\begin{array}{r}14 \\
(33.3)\end{array}$ & $\begin{array}{r}20 \\
(45.5)\end{array}$ & $\begin{array}{r}12 \\
(28.6)\end{array}$ & $\begin{array}{r}4 \\
(9.1)\end{array}$ \\
\hline Dizziness & $\begin{array}{r}17 \\
(40.5)\end{array}$ & $\begin{array}{r}10 \\
(22.7)\end{array}$ & $\begin{array}{r}12 \\
(28.6)\end{array}$ & $\begin{array}{r}12 \\
(27.3)\end{array}$ \\
\hline Abdominal cramp & $\begin{array}{r}9 \\
(21.4)\end{array}$ & $\begin{array}{r}4 \\
(9.1)\end{array}$ & $\begin{array}{r}1 \\
(2.4)\end{array}$ & $\begin{array}{r}9 \\
(20.5)\end{array}$ \\
\hline Dry mouth & - & $\begin{array}{r}1 \\
(2.3)\end{array}$ & - & - \\
\hline Diarrhea & - & - & - & $\begin{array}{r}3 \\
(6.8)\end{array}$ \\
\hline Extrapyramidal effect & - & - & - & - \\
\hline No adverse effect & $\begin{array}{r}2 \\
(4.8)\end{array}$ & $\begin{array}{r}10 \\
(22.7)\end{array}$ & $\begin{array}{r}7 \\
(16.7)\end{array}$ & $\begin{array}{r}12 \\
(27.3)\end{array}$ \\
\hline
\end{tabular}

Data within parenthesis are expressed as percentage

chemotherapy-induced vomiting.

The maximum score for appetite $(1.9 \pm 0.8)$ was observed at 48 hours both treatment groups. The score indices for nausea and vomiting were lower for ondansetron plus domperidone.

Most commonly recorded adverse events are shown in Table II. On Day 1, notable adverse events were headache, dizziness and abdominal cramp in ondansetrontreated group. Only 2 patients did not have any adverse effect whereas 10 patients in ondansetron and domperidone-treated group had no adverse effect. On day 2, increased number of patients in ondansetrontreated group was free from adverse effects. The number of patients complaining headache were reduced in ondansetron and domperidone-treated group (low in day 2 compared to on day 1 ).

\section{Discussion}

Chemotherapy-induced nausea and vomiting if inadequately controlled by antiemetic treatment, will limit a patient's ability and desire to eat and drink, significantly reduce quality of life, threaten the success of therapy, and may result in increased mortality, morbidity, and importantly, health care costs. Prevention of nausea and vomiting is critical in the management of patients with cancer.

The $5 \mathrm{HT}_{3}$-receptor antagonist are currently perceived as the gold standard antiemetic treatment providing effective control of acute nausea and vomiting, offering a substantial tolerability benefit over older conventional antiemetics. Ondansetron is the most widely used drug for the prevention of chemotherapy-induced nausea and vomiting. Previously, metoclopramide $\left(\mathrm{D}_{2}\right.$-receptor antagonist) was used. Domperidone is another $\mathrm{D}_{2}-$ receptor antagonist with anti-nauseant and prokinetic effects. Its principal advantage over metoclopramide is the lack of CNS side effects because of its poor penetration into the brain. Various types of antiemetic drugs can be combined, with the goal of increasing antiemetic efficacy or decreasing associated toxicity.

In this study, we compared the effect of ondansetron plus domperidone with the effect of ondansetron administered alone in the prevention of acute and delayed nausea and vomiting in breast cancer patients receiving moderately emetogenic chemotherapy. The severity of emesis is different in different chemotherapy schedule. For this reason, we used only the breast cancer patients using a definite schedule to compare the 
antiemetic effect of combined therapy and monotherapy.

Control of nausea and vomiting is particularly important during the initial cycle of chemotherapy as the development of anticipatory vomiting occurs more frequently in patients with poor control during previous chemotherapy treatment. It is probably more effective to prevent anticipatory emesis than to try to treat this conditioned response. Our study shows that ondansetron plus domperidone is able to prevent vomiting in most patients having their first cycle of cyclophosphamide-based chemotherapy.

The patients of both groups in our study were age matched. So there was no chance of variation of antiemetic response with age.

Ondansetron in combination with domperidone significantly decreased the chemotherapy-induced nausea and vomiting in comparison with ondansetron alone $(\mathrm{p}<0.001)$.

Ondansetron releases serotonin from enterochromaffin cells in the small intestinal mucosa contributes to the acute nausea and vomiting associated with chemotherapy. Serotonin activates receptors on vagal afferent fibers in the intestinal mucosa which relay sensory information to discrete brain areas involved in the genesis of nausea and vomiting (Anastasia, 2000). Ondansetron specially blocks the binding of serotonin to the receptors on the vagal nerves that trigger the emetic response (Doherty, 1999).

Cisplatin-induced emesis is completely controlled if serotonin stores are depleted by inhibition of serotonin synthesis (Barnes et al., 1987). Ondansetron is a highly selective $5-\mathrm{HT}_{3}$ receptor antagonist that is effective in preventing highly emetogenic cisplatin-induced nausea and vomiting (Cubeddu et al., 1990).

Kaasa et al., (1990) have shown intravenous ondansetron to be effective in the prevention of emesis associated with cyclophosphamide-based chemotherapies. Ondansetron is rapidly and completely absorbed when administered as a tablet.

Despite the better antiemetic efficacy observed with ondansetron in terms of nausea and vomiting, the control of emesis induced by FAC chemotherapy with ondansetron alone is still suboptimal, and could be improved by using domperidone in combination.

Domperidone acts by increasing the motility of the upper gastrointestinal tract and has a direct blocking effect on the chemoreceptor trigger zone. Thus, domperidone is an effective antiemetic medication (Watcha and White, 1992)

In a study by Esseboom et al. (1995) suggested that domperidone administered $20 \mathrm{mg}$ three times daily is more effective than ondansetron $8 \mathrm{mg}$ three times daily for the prevention of delayed nausea and/or vomiting which occur following highly emetogenic chemotherapy $(p<0.05)$. The major emetogenic agent in our chemotherapy combination, cyclophosphamide, is known to cause emesis with considerable delay from the time of administration (Fetting et al., 1982). With this view in our study, domperidone is added with ondansetron in management of nausea and vomiting induced by FAC regimen. In our study combined ondansetron and domperidone showed the more pronounced antiemetic effect.

After chemotherapy the patients experience the loss of appetite. We also observed the effect of drugs on appetite in patients having chemotherapy. Effect on appetite by ondansetron plus domperidone was significantly better than ondansetron alone in our study. Improvement in appetite indicates that ondansetron plus domperidone offered protection against nausea and maintaining appetite. The better appetite scores of co-administered drugs on appetite obviously attributed to their additive effect on appetite.

Common reported adverse effects of ondansetron when used for short-term period are constipation, headache, dizziness, abdominal cramp, etc. Common adverse effects of domperidone are dry mouth, loose motion, dizziness, headache, and galactorrhoea (Tripathi, 2003).

In this study the common adverse event headache was observed in both of the treated groups which was decreased intensity over the observation period during the 2nd day. Dizziness was experienced by both the groups which was similar in both the groups during the 2nd day of observation.

Both treatments were well-tolerated; the drug related adverse events reported in the two groups being minor and transient.

The results of this study demonstrate that ondansetron alone was not sufficient for controlling chemotherapyinduced nausea and vomiting but combination treatment of ondansetron plus domperidone brought a good control while maintaining normal appetite. 
Physicians concerned with the treatment of cancer patients may consider combined antiemetic therapy using ondansetron plus domperidone for effecttive control of chemotherapy-induced nausea and vomiting.

The co-administration of ondansetron and domperidone offers a promising new antiemetic management strategy for the prevention of chemotherapy-induced nausea and vomiting. The combination use of these agents provides good appetite status with no apparent risk of adverse events. In clinical practice, the combination regimen may provide a useful treatment for patients who are unable to attain a satisfactory antiemetic effect with ondansetron alone.

This study was conducted on a small number of patients. It was single center trial and follow-up was done for 48 hours. As the trial was fairly of short duration, analysis of long-term efficacy and safety was not possible.

Because direct comparison was carried out between two treatment groups of patients, the findings would have been more significant if a placebo group had been used. But a placebo controlled study was ethically not possible. Therefore, a control group was not included in this study. Further prospective interventional consecutive trials and longer follow-up period are suggested for better assessment of antiemetic efficacy and safety profile.

\section{References}

Anastasia PJ. Effectiveness of oral $5-\mathrm{HT}_{3}$ receptor antagonists for emetogenic chemotherapy. Oncol Nurs Forum 2000; 27: 483-93.

Barnes NM, Barrg JM, Costal B. Antagonism by parachlorophenylalanine of cisplatin-induced emesis. $\mathrm{Br} \mathrm{J}$ Pharmacol. 1987; 92: 649.

Bomford CK, Kunkler IH, Sherriff SB. Walter and Miller's Textbook of radiotherapy, 5th ed, London, Churchill Livingstone, 1993, pp 383-97.

Bonadonna G. Handbook of medical oncology. 3rd edi, Masson, Milano, 1988, p 407, 1076.

Cubeddu LX, Hoffmann IS, Fuenmayor NT, Finn AL. Efficacy of ondansetron and the role of serotonin in cisplatin-induced nausea and vomiting. N Engl J Med. 1990; 322: 810-16.

Doherty KM. Closing the gap in prophylactic antiemetic therapy: Patient factors in calculating the emetogenic potential of chemotherapy. Clin J Oncol Nurs. 1999; 3: 113-
19.

Esseboom EU, Rojer RA, Borm JJ, Statius van Eps LW. Prophylaxis of delayed nausea and vomiting after cancer chemotherapy. Neth J Med. 1995; 47: 12-17.

Fetting JH, Grochow LB, Folstein MF, Ettinger DS, Colvin M. The course of nausea and vomiting after high-dose cyclophosphamide. Cancer Treat Rep. 1982; 66: 1487-93.

Gregory RE, Ettinger DS. 5- $\mathrm{HT}_{3}$ receptor antagonists for the prevention of chemotherapy-induced nausea and vomiting: A comparison of their pharmacology and clinical efficacy. Drugs 1998; 55: 173-89.

Clavel M, Bonneterre J, d'Allens H, Paillarse JM. Oral ondansetron in the prevention of chemo-therapy-induced emesis in breast cancer patients. Eur J Cancer 1995; 31A: 1519.

Hesketh PJ, Harvey WH, Harker WG. A randomized, double blind comparison of intravenous ondansetron alone and in combination with intravenous dexamethasone in the prevention of high dose cisplatin-induced emesis. J Clin Oncol. 1994; 12: 596-600.

Holdsworth MT, Raisch DW, Winter SS, Chavez CM. Assesment of the emotogenic potential of intrathecal chemotherapy and response to prophylactic treatment with ondansetron. Support Care Cancer, 1998; 6: 132-38.

Huq SF. Cancer incidence in Bangladesh. J Bangladesh Coll Phys Surg. 1980; 5: 1-7.

Kassa S, Kvaloy S, Dicato MA, Ries F, Huys JV, Royer E, et al. A comparison of ondansetron with metoclopramide in the prophylaxis chemotherapy-induced nausea and vomiting: A randomized, double-blind study. Eur J Cancer. 1990; 26: 31114.

McQuaid KR. Drugs used in the treatment of gastrointestinal disease. In: Basic and clinical pharmacology, Katzung BG (ed), 9th ed, Boston, McGraw-Hill, 2004, p 1052.

Metz R. A randomized double blind comparison of ondansetron and metoclopramide in the prophylaxis of emesis produced by cyclophosphamide, fluouracil and doxorubicin or epirubicin chemotherapy. J Clin Oncol. 1990; 8: 1063-69.

Rodabaugh KJ, Bloss JD. Breast cancer prevention. Clin Obstet Gynecol. 2001; 44: 478-84.

Stewart L, Crawford SM, Taylor PA. The comparative effectiveness of ondansetron and granisetron in a once daily dosage in the prevention of nausea and vomiting caused by cisplatin: A double-blind clinical trial. Pharmaceutical J. 2000; 265: 59-62.

Tripathi KD. Emetics, antiemetics and other gastro-intestinal drugs. In: Essentials of medical pharmacology, 5th ed, Jaypee Brother's, New Delhi, 2003, pp 602-04. 
Watcha MF, White PF. Post-operative nausea and vomiting: Its etiology, treatment and prevention. Anesthesiology 1992; 77: $162-84$.
Wilde MI, Markham A. Ondansetron: A review of its pharmacology and preliminary clinical findings in novel applications. Drugs 1996; 52: 773-94.

\footnotetext{
Author Info

A. K. M. Mosharrof Hossain (Principal contact)
}

- - - - - - - - - - - - - - - - - - - - - - - - - - - - - - - - - - - - - - - - - - - - - - - - - - - - - - - - - - - 